\title{
FAKTOR-FAKTOR YANG MEMPENGARUHI MUTU KINERJA AUDITOR DENGAN ETOS KERJA SEBAGAI VARIABEL MODERATING
}

\author{
Nur Ummi Saraswati $S^{* 1}$, Tenriwaru ${ }^{2}$, Hajering ${ }^{3}$ \\ ${ }^{1,2}$ Magister Akuntansi, Program Pascasarjana Universitas Muslim Indonesia, Makassar, Indonesia \\ FEB Universitas Muslim Indonesia, Makassar, Indonesia \\ e-mail: umisaraswatis@gmail.com, cc: tenriwaru.umi@ac.id
}

\begin{abstract}
ABSTRAK
Penelitian ini bertujuan untuk menguji faktor-faktor yang mempengaruhi mutu kinerja auditor dengan etos kerja sebagai variabel moderating. Data yang diperoleh pada penelitian ini yaitu dari para Auditor yang bekerja di Kantor Inspektorat Provinsi Sulawesi Selatan yang menjadi responden. Untuk mengumpulkan data digunakan data primer yang diperoleh melalui pembagian lembar kuesioner yang berisi pernyataan-pernayataan yang ditujukan kepada 49 responden. Pada penelitian ini metode analisis data yang digunakan yaitu analisis regresi linier berganda dan analisis regresi moderasi. Hasil penelitian menunjukkan bahwa tekanan anggaran waktu, integritas, dan motivasi berpengaruh positif dan signifikan terhadap mutu kinerja auditor. Dan etos kerja berpengaruh positif dan signifikan terhadap hubungan antara tekanan anggaran waktu, integritas, motivasi terhadap mutu kinerja auditor. Hal ini berarti semakin tinggi tingkat tekanan anggaran waktu, integritas, motivasi, dan etos kerja seorang auditor maka akan sangat mempengaruhi mutu kinerja auditor yang akan semakin baik.
\end{abstract}

Kata Kunci: Tekanan Anggaran Waktu, Integritas, Motivasi, Etos Kerja, Mutu Kinerja Auditor

\begin{abstract}
This study aims to examine the factors that affect the quality of auditors' performance with work ethic as a moderating variable. The data obtained from this study are from auditors who work at the Inspectorate Office of South Sulawesi Province who were respondents. To collect data, primary data were used which were obtained through the distribution of questionnaires containing statements addressed to 49 respondents. In this study, the data analysis method used was multiple linear regression analysis and moderated regression analysis. The results showed that time budget pressure, integrity, and motivation had a positive and significant impact on the quality of auditor's performance. And work ethic has a positive and significant impact on the relationship between time budget pressure, integrity, motivation on the quality of auditor's perfsormance. This means that the higher the level of time budget pressure, integrity, motivation, and work ethic, will be the better the quality of the auditor's performance.
\end{abstract}

Keywords: Time Budget Pressure, Integrity, Motivation, Work Ethic, Quality of Auditor's Performance. 


\section{PENDAHULUAN}

Pengelolaan keuangan yang bwaik akan berdampak baik pula bagi suatu organisasi terkhusus organisasi pemerintah. Dengan dampak yang baik tersebut akan membuat organisasi pemerintah dikatakan berhasil dengan melihat pengelolaan/manajemen keuangan daerahnya yang dapat memberi suatu kesuksesan ataupun keberhasilan serta ketetapan kegiatan tersebut agar pemerintah bisa melakukan berbagai macam cara untuk memperkuat transparansi dan accountability financial management [1]. Untuk melihat pengelola keuangan yang baik dan tepat, tentu saja ada orang yang berkompeten dan mempunyai kinerja yang baik dalam melaksanakan pekerjaannya yang menyangkut hal tersebut. Bentuk tata kelola pemerintahan yang baik adalah pengelolaan keuangan yang efektif dan efisien [2]. Adapun tiga aspek yang mendukung terbentuknya kepemerintahan yang baik (good governance), yaitu pengawasan, pengendalian, dan pemeriksaan, [3].

Dapat dilihat bahwa terdapat Aturan Pemerintah RI No. 12 tahun 2017 di mana Penegakan maupun Pemeriksaan Penyelenggaraan Pemerintahan Daerah dapat mengiktikadkan posisi auditor intern dalam menciptakan good governance dalam hal pengawasan [4]. Adapun tim pengawas dilaksanakan oleh aparat pengawasan intern yaitu Inspektorat Provinsi, Kabupaten/Kota, Inspektorat Jenderal Departemen, dan Unit Pengawasan Lembaga Pemerintah Non Departemen dalam menjalankan tugas dan fungsinya. Oleh sebab itu, fungsi dan tanggung jawab Inspektorat daerah yaitu sebagai auditor internal yang bekerja untuk mencapai tujuan organisasi pemerintah daerah.

Inspektorat provinsi yaitu suatu lembaga yang merupakan kaki atau penopang dari Pemerintah Provinsi, yang bergerak pada bidang pemeriksaan ataupun pengawasan yang langsung dipimpin oleh Kepala Inspektorat dan berada dibawah dan bertanggungjawab langsung kepada Gubernur. Peranan dari Inspektorat Provinsi itu sendiri yaitu menyediakan laporan keuangan yang dapat diterima umum serta akuntabel dalam hal membantu Gubernur. Adapun tugas dan wewenang dari Inspektorat Provinsi, Kabupaten/Kota secara umum diatur dalam pasal 4 Peraturan Menteri Dalam Negeri Nomor 64 Tahun 2007 [5].

Berdasarkan Peraturan Gubernur Sulawesi Selatan Tahun 2008, Inspektorat Provinsi Sulawesi Selatan mempunyai tugas pokok yaitu menjadi kaki tangan Gubernur dalam hal pengawasan yaitu merumuskan kebijaksanaan teknis dibidang pengawasam/pemeriksaan; menyusun rencana dan program, melaksanakan pengendalian teknis operasional pengawasan; dan melaksanakan koordinasi pengawasan dan tindak lanjut hasil pengawasan [6]. 
Beberapa waktu terakhir, Auditor Intern Pemerintah telah menjadi perhatian terpaut dengan kinerja yang sangat drastis melemah, khususnya kinerja pemerintah daerah. LACC atau biasa disebut Lembaga Anti Corruption Commite pada tahun 2017 menyoroti kinerja Inspektorat Kota Makassar yang dinilai harus dilakukan analisa terkait dengan beberapa kasus korupsi dalam kurun 2 tahun terkahir di Kota Makassar [7]. Tugas Inspektorat menjadi pelaksana terdepan pembangunan daerah, terkhusus Provinsi, Kabupaten, dan Kota. Daerah akan menerima banyak Anggaran Pendapatan dan Belanja Negara (APBN) seperti dana alokasi umum (DAU) dan dana alokasi khusus (DAK). Dengan ini, usaha untuk memberi peningkatan terhadap efektivitas inspektorat untuk pengawasan keuangan di daerah semakin genting.

Dalam fenomena yang telah dijelaskan, maka seorang auditor diharapkan dapat melakukan kinerja yang lebih baik. Penelitian ini bertujuan untuk mengetahui faktor-faktor apa sajakah yang dapat mempengaruhi kinerja auditor dalam proses mengaudit agar kinerjanya bisa cenderung membaik.

\section{METODE PENELITIAN}

Penelitian ini dilaksanakan selama bulan April 2020 sampai dengan Juni 2020 dengan populasi seluruh auditor yang bekerja di Kantor Inspektorat Daerah Provinsi Sulawesi Selatan yang berjumlah 49 orang auditor. Data dikumpulkan melalui media kuesioner yang di dalamnya berisikan pernyataan-pernyataan yang diisi oleh setiap responden.

\subsection{Kerangka Pemikiran}

Berikut kerangka pemikiran pada penelitian ini adalah sebagai berikut:

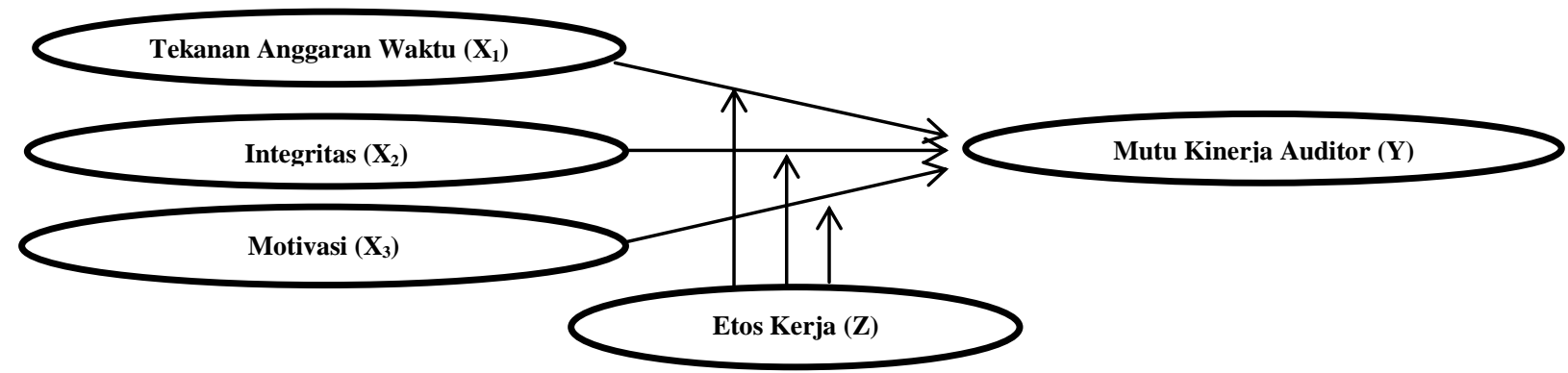

Gambar 1. Kerangka Konseptual 


\subsection{Hipotesis Penelitian}

$\mathrm{H}_{1}$ : Tekanan Anggaran Waktu Berpengaruh Positif dan Signifikan Terhadap Mutu Kinerja Auditor

$\mathrm{H}_{2}$ : Integritas Berpengaruh Positif dan Signifikan Terhadap Mutu Kinerja Auditor

$\mathrm{H}_{3}$ : Motivasi Berpengaruh Positif dan Signifikan Terhadap Mutu Kinerja Auditor

$\mathrm{H}_{4}$ : Etos Kerja Berpengaruh Positif dan Signifikan Terhadap Hubungan Antara Tekanan Anggaran Waktu dengan Mutu Kinerja Auditor

$\mathrm{H}_{5}$ : Etos Kerja Berpengaruh Positif dan Signifikan Terhadap Hubungan Antara Integritas dengan Mutu Kinerja Auditor

$\mathrm{H}_{6}$ : Etos Kerja Berpengaruh Positif dan Signifikan Terhadap Hubungan Antara Motivasi dengan Mutu Kinerja Auditor

\subsection{Metode Analisis Data}

Metode statistik yang digunakan dalam menguji hipotesis adalah menggunakan analisis regresi linear berganda dan metode MRA (Moderated Regression Analysis) dengan alat bantu perangkat lunak SPSS. Apabila data telah rampung, langkah berikutnya ialah menganalisis data berupa uji instrumen penelitian, uji asumsi klasik, dan uji hipotesis. Persamaan yang digunakan dalam uji hipotesis (MRA) :

$$
\begin{aligned}
& Y=\beta_{0}+\beta_{1} X_{1}+\beta_{2} X_{2}+\beta_{3} X_{3}+\beta_{4} Z+\varepsilon \ldots \ldots .(\text { Model } 1) \\
& Y=\beta_{0}+\beta_{1} X_{1}+\beta_{4} Z+\beta_{5} X_{1} Z+\varepsilon \ldots \ldots \ldots \ldots .(\text { Model } 2) \\
& Y=\beta_{0}+\beta_{2} X_{2}+\beta_{4} Z+\beta_{5} X_{2} Z+\varepsilon \ldots \ldots \ldots \ldots .(\text { Model } 3) \\
& Y=\beta_{0}+\beta_{3} X_{3}+\beta_{4} Z+\beta_{5} X_{3} Z+\varepsilon \ldots \ldots \ldots \ldots .(\text { Model } 4)
\end{aligned}
$$

Keterangan:

Y : Mutu Kinerja Auditor

$\beta_{0} \quad$ : Konstanta

$\mathrm{X}_{1} \quad$ : Tekanan Anggaran Waktu

$\mathrm{X}_{2} \quad$ : Integritas

$\mathrm{X}_{3} \quad$ : Motivasi

$\mathrm{Z} \quad$ : Etos Kerja

$\beta_{1},-\beta_{6}:$ Koefisien Regresi

$\mathrm{X}_{1} \mathrm{Z} \quad$ : Interaksi antara tekanan anggaran waktu dan etos kerja

$\mathrm{X}_{2} \mathrm{Z} \quad$ : Interaksi antara integritas dan etos kerja

$\mathrm{X}_{3} \mathrm{Z} \quad$ : Interaksi antara motivasi dan etos kerja

$\varepsilon$ : Kesalahan Residual

\subsection{Definisi Operasional Variabel Penelitian}

1) Tekanan Anggaran Waktu ialah kondisi yang menuntut auditor agar mengefisienkan anggaran waktu yang sudah dibuat atau adanya pembatasan waktu anggaran yang ketat dan kaku. Adapun indikator tekanan anggaran waktu yaitu ketepatan waktu, pemenuhan 
target dengan waktu yang ditentukan, kelonggaran waktu audit, dan beban yang ditanggung dengan keterbatasan waktu.

2) Integritas adalah suatu kriteria yang mendasar bagi setiap individual yang melekat pada pengakuan profesionalnya. Integritas adalah sikap yang harus dimiliki seorang auditor untuk selalu berperilaku jujur dan transparansi, serta bijaksana, berani, dan harus bertanggung jawab untuk melakukan setiap tugasnya. Adapun indikator dari integritas yaitu kejujuran auditor, keberanian auditor, sikap bijaksana auditor, dan tanggung jawab auditor.

3) Motivasi ialah kemauan seseorang untuk melaksanakan suatu tindakan baik secara sadar untuk pencapaian tujuan organisasi sesuai tugas dan tanggung jawab yang diembannya. Adapun indikator dari motivasi yaitu kebutuhan fisiologis, keamanan, sosial, penghargaan, dan kebutuhan aktualisasi diri.

4) Etos Kerja adalah serangkaian tindakan positif yang berasal dari keyakinan fundamental yang disertai komitmen total pada paradigma kerja yang integral. Adapun indikator dari etos kerja yaitu kerja adalah rahmat, amanah, panggilan, aktualisasi, ibadah, seni, kehormatan maupun kerja adalah pelayanan.

5) Mutu Kinerja Auditor adalah kualitas atas pencapaian hasil dari tugas yang dikerjakan. Setiap orang memiliki kinerja yang dipengaruhi oleh beberapa faktor yang dibagi menjadi 3 kelompok, yaitu kompetensi individu orang yang bersangkutan, dukungan organisasi dan dukungan manajemen. Adapun indikator mutu kinerja auditor yaitu efektivitas dan efisiensi, tanggung jawab, disiplin, dan inisiatif.

\section{HASIL PENELITIAN DAN PEMBAHASAN}

\subsection{Hasil Penelitian}

Tabel 1. Distribusi Jawaban Responden Variabel Tekanan Anggaran Waktu $\left(\mathrm{X}_{1}\right)$

\begin{tabular}{|c|c|c|c|c|c|c|c|c|c|}
\hline \multirow{2}{*}{\multicolumn{2}{|c|}{ Item }} & \multicolumn{6}{|c|}{ Frekuensi Skor dan Persentase } & \multirow{2}{*}{$\begin{array}{l}\text { Total } \\
\text { Skor }\end{array}$} & \multirow{2}{*}{$\begin{array}{c}\text { Rata- } \\
\text { rata }\end{array}$} \\
\hline & & 1 & 2 & 3 & 4 & 5 & $\mathrm{~N}$ & & \\
\hline \multicolumn{9}{|c|}{ Indikator 1} & 4,08 \\
\hline 1 & $\mathrm{~F}$ & 0 & 0 & 8 & 23 & 6 & 37 & 146 & 3,95 \\
\hline 2 & $\mathrm{~F}$ & 0 & 0 & 2 & 25 & 10 & 37 & 156 & 4,22 \\
\hline \multicolumn{9}{|c|}{ Indikator 2} & 4,19 \\
\hline 3 & $\mathrm{~F}$ & 0 & 0 & 2 & 26 & 9 & 37 & 155 & 4,19 \\
\hline \multicolumn{9}{|c|}{ Indikator 3} & 4,00 \\
\hline 4 & $\mathrm{~F}$ & 0 & 0 & 4 & 29 & 4 & 37 & 148 & 4,00 \\
\hline \multicolumn{9}{|c|}{ Indikator 4} & 3,11 \\
\hline 5 & $\mathrm{~F}$ & 4 & 4 & 13 & 16 & 0 & 37 & 115 & 3,11 \\
\hline \multicolumn{8}{|c|}{ garan Waktu } & 144 & 3,84 \\
\hline
\end{tabular}

Sumber: Data Primer yang Diolah 2020 
Pada tabel 1 menggambarkan bahwa indikator yang paling mendominasi untuk membentuk variabel tekanan anggaran waktu yaitu pada indikator pemenuhan target dengan waktu yang ditentukan dengan nilai rata-rata 4,19 dan indikator yang memberikan proporsi terkecil dalam membentuk variabel ini yaitu pada indikator beban yang ditanggung dengan keterbatasan waktu dengan nilai rata-rata 3,11.

Tabel 2. Distribusi Jawaban Responden Variabel Integritas $\left(\mathbf{X}_{2}\right)$

\begin{tabular}{|c|c|c|c|c|c|c|c|c|c|}
\hline \multirow{2}{*}{\multicolumn{2}{|c|}{ Item }} & \multicolumn{6}{|c|}{ Frekuensi Skor dan Persentase } & \multirow{2}{*}{$\begin{array}{l}\text { Total } \\
\text { Skor }\end{array}$} & \multirow{2}{*}{$\begin{array}{l}\text { Rata- } \\
\text { rata }\end{array}$} \\
\hline & & 1 & 2 & 3 & 4 & 5 & $\mathrm{~N}$ & & \\
\hline \multicolumn{9}{|c|}{ Indikator 1. Kejujuran Auditor } & 4,21 \\
\hline 1 & $\mathrm{~F}$ & 0 & 0 & 3 & 24 & 10 & 37 & 155 & 4,19 \\
\hline 2 & $\mathrm{~F}$ & 0 & 0 & 3 & 23 & 11 & 37 & 156 & 4,22 \\
\hline \multicolumn{9}{|c|}{ Indikator 2. Keberanian Auditor } & 4,19 \\
\hline 3 & $\mathrm{~F}$ & 0 & 0 & 4 & 22 & 11 & 37 & 155 & 4,19 \\
\hline 4 & $\mathrm{~F}$ & 0 & 0 & 0 & 30 & 7 & 37 & 155 & 4,19 \\
\hline \multicolumn{9}{|c|}{ Indikator 3. Sikap Bijaksana Auditor } & 4,11 \\
\hline 5 & $\mathrm{~F}$ & 0 & 0 & 2 & 30 & 5 & 37 & 151 & 4,08 \\
\hline 6 & $\mathrm{~F}$ & 0 & 0 & 0 & 32 & 5 & 37 & 153 & 4,13 \\
\hline \multicolumn{9}{|c|}{ Indikator 4. Tanggung Jawab Auditor } & 4,12 \\
\hline 7 & $\mathrm{~F}$ & 0 & 0 & 5 & 22 & 10 & 37 & 153 & 4,13 \\
\hline 8 & $\mathrm{~F}$ & 0 & 0 & 5 & 20 & 12 & 37 & 155 & 4,19 \\
\hline 9 & $\mathrm{~F}$ & 0 & 0 & 7 & 22 & 8 & 37 & 149 & 4,03 \\
\hline \multicolumn{8}{|c|}{ Mean Variabel Integritas } & 154 & 4,16 \\
\hline
\end{tabular}

Sumber: Data Primer yang Diolah 2020

Pada tabel 2 menjelaskan bahwa indikator yang paling mendominasi untuk membentuk variabel integritas yaitu pada indikator kejujuran auditor dengan nilai rata-rata 4,21 dan indikator sikap bijaksana auditor memberikan proporsi terkecil dalam membentuk variabel ini yaitu dengan nilai rata-rata 4,11 .

Tabel 3. Distribusi Jawaban Responden Variabel Motivasi $\left(\mathbf{X}_{3}\right)$

\begin{tabular}{|c|c|c|c|c|c|c|c|c|c|}
\hline \multirow{2}{*}{\multicolumn{2}{|c|}{ Item }} & \multicolumn{6}{|c|}{ Frekuensi Skor dan Persentase } & \multirow[t]{2}{*}{ Total Skor } & \multirow{2}{*}{$\begin{array}{c}\text { Rata- } \\
\text { rata }\end{array}$} \\
\hline & & 1 & 2 & 3 & 4 & 5 & $\mathrm{~N}$ & & \\
\hline \multicolumn{9}{|c|}{ Indikator 1. Kebutuhan Fisiologis } & 3,93 \\
\hline 1 & $\mathrm{~F}$ & 0 & 2 & 3 & 29 & 3 & 37 & 144 & 3,89 \\
\hline 2 & $\mathrm{~F}$ & 0 & 0 & 6 & 26 & 5 & 37 & 147 & 3,97 \\
\hline \multicolumn{9}{|c|}{ Indikator 2. Kebutuhan Keamanan } & 4,13 \\
\hline 3 & $\mathrm{~F}$ & 0 & 0 & 3 & 26 & 8 & 37 & 153 & 4,13 \\
\hline \multicolumn{9}{|c|}{ Indikator 3. Kebutuhan Sosial } & 4,05 \\
\hline 4 & $\mathrm{~F}$ & 0 & 0 & 6 & 24 & 7 & 37 & 149 & 4,03 \\
\hline 5 & $\mathrm{~F}$ & 0 & 0 & 4 & 26 & 7 & 37 & 151 & 4,08 \\
\hline \multicolumn{9}{|c|}{ Indikator 4. Kebutuhan Penghargaan } & 3,54 \\
\hline 6 & $\mathrm{~F}$ & 0 & 2 & 18 & 12 & 5 & 37 & 131 & 3,54 \\
\hline \multicolumn{9}{|c|}{ Indikator 5. Kebutuhan Aktualisasi Diri } & 3,90 \\
\hline 7 & $\mathrm{~F}$ & 0 & 2 & 13 & 14 & 8 & 37 & 139 & 3,76 \\
\hline 8 & $\mathrm{~F}$ & 0 & 0 & 9 & 18 & 10 & 37 & 149 & 4,03 \\
\hline \multicolumn{8}{|c|}{ Mean Variabel Motivasi } & 145 & 3,91 \\
\hline
\end{tabular}

Sumber: Data Primer yang Diolah 2020 
Pada tabel 3 menjelaskan bahwa indikator yang lebih mendominasi untuk membentuk suatu variabel motivasi yaitu pada indikator kebutuhan keamanan dengan nilai rata-rata 4,13 dan indikator kebutuhan penghargaan memberikan proporsi terkecil dalam membentuk variabel ini yaitu dengan nilai rata-rata 3,54.

Tabel 4. Distribusi Jawaban Responden Variabel Mutu Kinerja Auditor (Y)

\begin{tabular}{|c|c|c|c|c|c|c|c|c|c|}
\hline \multirow{2}{*}{\multicolumn{2}{|c|}{ Item }} & \multicolumn{6}{|c|}{ Frekuensi Skor dan Persentase } & \multirow[t]{2}{*}{ Total Skor } & \multirow[t]{2}{*}{ Rata-rata } \\
\hline & & 1 & 2 & 3 & 4 & 5 & $\mathrm{~N}$ & & \\
\hline \multicolumn{9}{|c|}{ Indikator 1. Efektivitas dan Efisiensi } & 4,14 \\
\hline 1 & $\mathrm{~F}$ & 0 & 0 & 4 & 21 & 12 & 37 & 156 & 4,22 \\
\hline 2 & $\mathrm{~F}$ & 0 & 0 & 7 & 21 & 9 & 37 & 150 & 4,05 \\
\hline \multicolumn{9}{|c|}{ Indikator 2. Tanggung Jawab } & 3,85 \\
\hline 3 & $\mathrm{~F}$ & 0 & 1 & 16 & 15 & 5 & 37 & 135 & 3,65 \\
\hline 4 & $\mathrm{~F}$ & 0 & 0 & 7 & 21 & 9 & 37 & 150 & 4,05 \\
\hline \multicolumn{9}{|c|}{ Indikator 3. Disiplin } & 4,00 \\
\hline 5 & $\mathrm{~F}$ & 0 & 0 & 7 & 22 & 8 & 37 & 149 & 4,03 \\
\hline 6 & $\mathrm{~F}$ & 0 & 0 & 9 & 20 & 8 & 37 & 147 & 3,97 \\
\hline \multicolumn{9}{|c|}{ Indikator 4. Inisiatif } & 3,97 \\
\hline 7 & $\mathrm{~F}$ & 0 & 0 & 9 & 20 & 8 & 37 & 147 & 3,97 \\
\hline 8 & $\mathrm{~F}$ & 0 & 0 & 8 & 22 & 7 & 37 & 147 & 3,97 \\
\hline \multicolumn{8}{|c|}{ Mean Variabel Mutu Kinerja Auditor } & 148 & 3,99 \\
\hline
\end{tabular}

Sumber: Data Primer yang Diolah 2020

Pada tabel 4 menjelaskan bahwa indikator yan lebih mendominasi untuk membentuk suatu variabel mutu kinerja auditor yaitu pada indikator efektivitas dan efisiensi dengan nilai rata-rata 4,14 dan indikator tanggung jawab memberikan proporsi terkecil dalam membentuk variabel ini yaitu dengan nilai rata-rata 3,85.

Tabel 5. Distribusi Jawaban Responden Variabel Etos Kerja (Z)

\begin{tabular}{|c|c|c|c|c|c|c|c|c|c|}
\hline \multirow{2}{*}{\multicolumn{2}{|c|}{ Item }} & \multicolumn{6}{|c|}{ Frekuensi Skor dan Persentase } & \multirow[t]{2}{*}{ Total Skor } & \multirow[t]{2}{*}{ Rata-rata } \\
\hline & & 1 & 2 & 3 & 4 & 5 & $\mathrm{~N}$ & & \\
\hline \multicolumn{9}{|c|}{ Indikator 1. Kerja adalah Rahmat } & 4,15 \\
\hline 1 & $\mathrm{~F}$ & 0 & 0 & 4 & 24 & 9 & 37 & 153 & 4,13 \\
\hline 2 & F & 0 & 0 & 4 & 23 & 10 & 37 & 154 & 4,16 \\
\hline \multicolumn{9}{|c|}{ Indikator 2. Kerja adalah Amanah } & 3,36 \\
\hline 3 & $\mathrm{~F}$ & 6 & 2 & 9 & 18 & 2 & 37 & 119 & 3,22 \\
\hline 4 & $\mathrm{~F}$ & 6 & 0 & 4 & 24 & 3 & 37 & 129 & 3,49 \\
\hline \multicolumn{9}{|c|}{ Indikator 3. Kerja adalah Panggilan } & 4,27 \\
\hline 5 & $\mathrm{~F}$ & 0 & 0 & 4 & 19 & 14 & 37 & 158 & 4,27 \\
\hline \multicolumn{9}{|c|}{ Indikator 4. Kerja adalah Aktualisasi } & 4,16 \\
\hline 6 & $\mathrm{~F}$ & 0 & 0 & 4 & 23 & 10 & 37 & 154 & 4,16 \\
\hline \multicolumn{9}{|c|}{ Indikator 5. Kerja adalah Ibadah } & 4,15 \\
\hline 7 & $\mathrm{~F}$ & 0 & 0 & 4 & 22 & 11 & 37 & 155 & 4,19 \\
\hline 8 & $\mathrm{~F}$ & 0 & 0 & 4 & 25 & 8 & 37 & 152 & 4,11 \\
\hline \multicolumn{9}{|c|}{ Indikator 6. Kerja adalah Seni } & 3,69 \\
\hline 9 & $\mathrm{~F}$ & 2 & 5 & 9 & 18 & 3 & 37 & 126 & 3,41 \\
\hline 10 & $\mathrm{~F}$ & 0 & 0 & 7 & 24 & 6 & 37 & 147 & 3,97 \\
\hline \multicolumn{9}{|c|}{ Indikator 7. Kerja adalah Kehormatan } & 2,91 \\
\hline 11 & $\mathrm{~F}$ & 3 & 10 & 14 & 9 & 1 & 37 & 106 & 2,86 \\
\hline 12 & $\mathrm{~F}$ & 3 & 9 & 12 & 12 & 1 & 37 & 110 & 2,97 \\
\hline \multicolumn{9}{|c|}{ Indikator 8. Kerja adalah Pelayanan } & 4,00 \\
\hline 13 & $\mathrm{~F}$ & 0 & 0 & 9 & 19 & 9 & 37 & 148 & 4,00 \\
\hline \multicolumn{8}{|c|}{ Mean Variabel Etos Kerja } & 139 & 3,84 \\
\hline
\end{tabular}

Sumber: Data Primer yang Diolah 2020 
Pada tabel 5 menjelaskan bahwa indikator yang lebih mendominasi untuk membentuk suatu variabel etos kerja yaitu pada indikator kerja adalah panggilan, indikator tersebut mempunyai nilai rata-rata 4,27 dan indikator kerja adalah kehormatan memberikan proporsi terkecil dalam membentuk variabel etos kerja yaitu dengan nilai rata-rata 2,91.

\section{Hasil Uji Validitas}

Tabel 6. Uji Validitas Data

\begin{tabular}{|c|c|c|c|c|}
\hline Variabel & Pernyataan & $\mathbf{r}_{\text {hitung }}$ & $\mathbf{r}_{\text {tabel }}$ & Keterangan \\
\hline \multirow{5}{*}{$\begin{array}{c}\text { Tekanan Anggaran } \\
\text { Waktu }\left(\mathrm{X}_{1}\right)\end{array}$} & 1 & $0,935 * *$ & 0,325 & \multirow{5}{*}{ Valid } \\
\hline & 2 & $0,674 * *$ & 0,325 & \\
\hline & 3 & $0,773 * *$ & 0,325 & \\
\hline & 4 & $0,655 * *$ & 0,325 & \\
\hline & 5 & $0,694 * *$ & 0,325 & \\
\hline \multirow{9}{*}{ Integritas $\left(\mathrm{X}_{2}\right)$} & 1 & $0,727 * *$ & 0,325 & \multirow{9}{*}{ Valid } \\
\hline & 2 & $0,826 * *$ & 0,325 & \\
\hline & 3 & $0,693 * *$ & 0,325 & \\
\hline & 4 & $0,716 * *$ & 0,325 & \\
\hline & 5 & $0,714 * *$ & 0,325 & \\
\hline & 6 & $0,800 * *$ & 0,325 & \\
\hline & 7 & $0,769 * *$ & 0,325 & \\
\hline & 8 & $0,824 * *$ & 0,325 & \\
\hline & 9 & $0,891 * *$ & 0,325 & \\
\hline \multirow{8}{*}{ Motivasi $\left(\mathrm{X}_{3}\right)$} & 1 & $0,733 * *$ & 0,325 & \multirow{8}{*}{ Valid } \\
\hline & 2 & $0,774 * *$ & 0,325 & \\
\hline & 3 & $0,890 * *$ & 0,325 & \\
\hline & 4 & $0,853 * *$ & 0,325 & \\
\hline & 5 & $0,909 * *$ & 0,325 & \\
\hline & 6 & $0,859 * *$ & 0,325 & \\
\hline & 7 & $0,735 * *$ & 0,325 & \\
\hline & 8 & $0,792 * *$ & 0,325 & \\
\hline \multirow{8}{*}{$\begin{array}{l}\text { Mutu Kinerja } \\
\text { Auditor (Y) }\end{array}$} & 1 & $0,873 * *$ & 0,325 & \multirow{8}{*}{ Valid } \\
\hline & 2 & $0,885 * *$ & 0,325 & \\
\hline & 3 & $0,519 * *$ & 0,325 & \\
\hline & 4 & $0,956 * *$ & 0,325 & \\
\hline & 5 & $0,978 * *$ & 0,325 & \\
\hline & 6 & $0,946 * *$ & 0,325 & \\
\hline & 7 & $0,926 * *$ & 0,325 & \\
\hline & 8 & $0,870 * *$ & 0,325 & \\
\hline \multirow[t]{13}{*}{ Etos Kerja (Z) } & 1 & $0,681 * *$ & 0,325 & \multirow{13}{*}{ Valid } \\
\hline & 2 & $0,667 * *$ & 0,325 & \\
\hline & 3 & $0,567 * *$ & 0,325 & \\
\hline & 4 & $0,503 * *$ & 0,325 & \\
\hline & 5 & $0,703 * *$ & 0,325 & \\
\hline & 6 & $0,667 * *$ & 0,325 & \\
\hline & 7 & $0,710 * *$ & 0,325 & \\
\hline & 8 & $0,651 * *$ & 0,325 & \\
\hline & 9 & $0,553 * *$ & 0,325 & \\
\hline & 10 & $0,734 * *$ & 0,325 & \\
\hline & 11 & $0,499 * *$ & 0,325 & \\
\hline & 12 & $0,469 * *$ & 0,325 & \\
\hline & 13 & $0,528 * *$ & 0,325 & \\
\hline
\end{tabular}


Diketahui bahwa pada hasil uji validitas, variabel tekanan anggaran waktu, integritas, motivasi, mutu kinerja auditor, dan etos kerja memiliki nilai signifikan lebih kecil dari 0,05 dan nilai pearson corelation ( $r$ hitung) lebih besar dari $r$ tabel dengan nilai $r$ tabel yaitu 0,325 sehingga dapat disimpulkan bahwa seluruh item pernyataan dalam penelitian ini valid.

\section{Hasil Uji Reliabilitas}

Tabel 7. Uji Reliabilitas

\begin{tabular}{|l|c|c|}
\hline \multicolumn{1}{|c|}{ Variable } & Cronbach's Alpha & Keputusan \\
\hline Tekanan Anggaran Waktu &, 857 & Reliable \\
Integritas &, 855 & Reliable \\
Motivasi &, 813 & Reliable \\
Mutu Kinerja Auditor &, 808 & Reliable \\
Etos Kerja &, 840 & Reliable \\
\hline
\end{tabular}

Sumber: Data Primer yang Diolah 2020

Diketahui bahwa variabel tekanan anggaran waktu, integritas, motivasi, mutu kinerja auditor, dan etos kerja memiliki nilai cronbach's alpha >0,6. Hal ini mengindikasikan komponen pernyataan yang terdapat dalam penelitian ini adalah reliabel. Oleh karena itu, pernyataan yang digunakan dalam setiap variabel penelitian ini akan mendapatkan data yang konsisten, sehingga walaupun diajukan kembali akan didapatkan jawaban yang relatif sama dengan jawaban sebelumnya.

\section{Hasil Uji Normalitas}

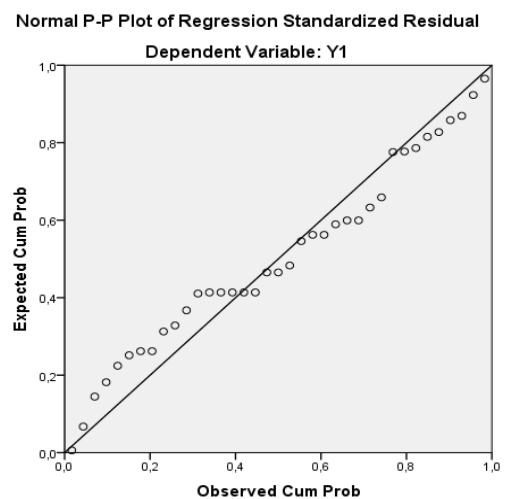

\section{Gambar 2. Uji Normalitas menggunakan Grafik P-Plot}

Dari Gambar 2 memperlihatkan penyebaran titik-titik berada disekitar garis diagonal serta mengikuti arah garis diagonal. Hal tersebut mengindikasikan bahwa model regresi layak digunakan sebab telah memenuhi asumsi normalitas. 


\section{Hasil Uji Multikolinieritas}

Tabel 8. Uji Multikolinieritas

\begin{tabular}{|c|c|c|}
\hline \multicolumn{3}{|c|}{ Coefficients $^{\mathrm{a}}$} \\
\hline \multirow{2}{*}{ Model } & \multicolumn{2}{|c|}{ Collinerity Statistics } \\
\hline & Tolerance & VIF \\
\hline Tekanan Anggaran Waktu & ,211 & 1,497 \\
\hline Integritas & 262 & 2,162 \\
\hline Motivasi & ,295 & 2,532 \\
\hline Etos Kerja & 249 & 1,335 \\
\hline
\end{tabular}

Variabel tekanan anggaran waktu, integritas, motivasi, dan etos kerja memiliki nilai tolerance $>0,1$ dan VIF $<10$. Maka dari itu, model persamaan regresi dalam penelitian ini tidak terdapat gejala multikolonearitas dan data tersebut bisa digunakan dalam penelitian ini.

\section{Hasil Uji Heteroskedastisitas}

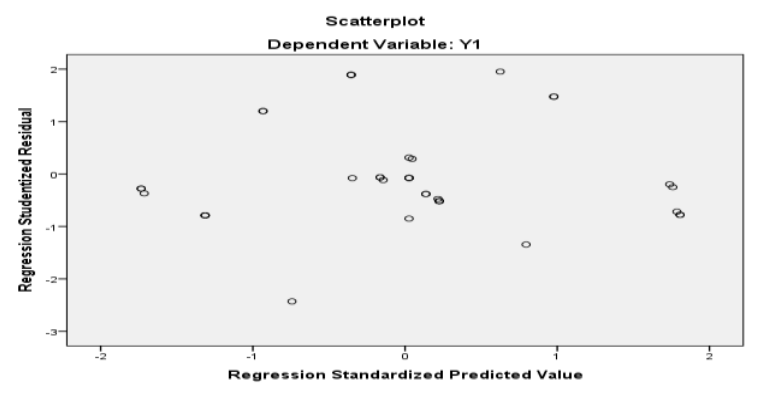

\section{Gambar 3. Uji Heteroskedastisitas menggunakan Grafik Scatterplot}

Gambar di atas menunjukkan grafik scatterplot yang menjelaskan bahwa penyebaran data/titik-titik tersebut menyebar pada sumbu Y serta tidak membentuk sebuah pola tertentu sehingga mengindikasikan bahwa model tersebut tidak terjadi heteroskedastisitas.

\section{Pengujian Model 1}

Tabel 9. Hasil Uji Koefisien Determinasi Model 1

\begin{tabular}{|c|c|c|c|c|}
\hline \multicolumn{5}{|c|}{ Model Summary } \\
\hline Model & $\mathrm{R}$ & $\mathrm{R}_{2}$ & Standart Error & Durbin-Watson \\
\hline 1 & $909^{\mathrm{a}}$ & ,826 & ,26281 & 2,181 \\
\hline
\end{tabular}

Berdasarkan tabel di atas menjelaskan bahwa nila $\mathrm{R}_{2}$ (koefisien determinasi) sebesar 0,826 atau $82,6 \%$. Yang artinya variabel mutu kinerja auditor bisa dijelaskan oleh tekanan anggaran waktu, integritas, motivasi, dan etos kerja sebesar $82,6 \%$ dan selebihnya $17,4 \%$, akan dijelaskan oleh variabel lain diluar model penelitian ini. 
Tabel 10. Hasil Uji t Model 1

\begin{tabular}{|c|c|c|c|c|c|c|}
\hline \multicolumn{7}{|c|}{ Coefficients $^{\mathrm{a}}$} \\
\hline \multirow{2}{*}{\multicolumn{2}{|c|}{ Model }} & \multicolumn{2}{|c|}{ Unstandardized Coefficients } & \multirow{2}{*}{$\begin{array}{c}\text { Standardized Coefficients } \\
\text { Beta }\end{array}$} & \multirow[b]{2}{*}{$\mathrm{t}$} & \multirow[b]{2}{*}{ Sig. } \\
\hline & & $\mathrm{B}$ & Standart Error & & & \\
\hline \multirow[t]{5}{*}{1} & (Constant) & 1,171 &, 115 & & 10,183 & 000 \\
\hline & $\mathrm{X} 1$ & ,311 & 116 & ,307 & 2,681 & 015 \\
\hline & $\mathrm{X} 2$ &, 390 &, 105 &, 402 & 3,713 &, 001 \\
\hline & $\mathrm{X} 3$ & ,728 & 132 & ,716 & 5,515 &, 000 \\
\hline & Z (Moderator) &, 313 &, 072 & ,372 & 4,368 &, 000 \\
\hline
\end{tabular}

Sumber: Data Primer yang Diolah 2020

Dari tabel di atas tersebut diketahui persamaan regresi linear sebagai berikut:

$$
Y=1,171+0,311 X_{1}+0,390 X_{2}+0,728 X_{3}+0,313 Z
$$

\section{Pengujian Model 2}

Tabel 11. Hasil Uji Koefisien Determinasi Model 2

\begin{tabular}{|l|c|c|c|}
\hline \multicolumn{4}{|c|}{ Model Summary } \\
\hline Model & $\mathrm{R}$ & $\mathrm{R}_{2}$ & Estimasi Standar Eror \\
\hline 1 &, 703 &, 495 &, 44122 \\
\hline
\end{tabular}

Berdasarkan tabel di atas, menjelaskan bahwa nilai $\mathrm{R}_{2}$ (koefisien determinasi) yaitu 0,495 atau 49,5\%. Yang artinya mutu kinerja auditor ini mampu dijelaskan oleh variabel tekanan anggaran waktu, etos kerja, dan variabel interaksi antara tekanan anggaran waktu dengan etos kerja sebesar 49,5\% dan sisanya yaitu 50,5\%, akan dijelaskan oleh variabel lain yang berada diluar dari variabel model penelitian ini.

Tabel 12. Hasil Uji t Model 2

\begin{tabular}{|c|c|c|c|c|c|c|}
\hline \multicolumn{7}{|c|}{ Coefficients $^{\mathrm{a}}$} \\
\hline \multirow{2}{*}{\multicolumn{2}{|c|}{ Model }} & \multicolumn{2}{|c|}{ Unstandardized Coefficients } & \multirow{2}{*}{$\begin{array}{c}\text { Standardized Coefficients } \\
\text { Beta } \\
\end{array}$} & \multirow[b]{2}{*}{$\mathrm{t}$} & \multirow[b]{2}{*}{ Sig. } \\
\hline & & $\mathrm{B}$ & Standart Error & & & \\
\hline 1 & (Constant) & 6,604 & 4,767 & & 1,385 &, 175 \\
\hline & $\mathrm{X} 1$ & ,425 &, 114 & ,479 & 3,729 & ,000 \\
\hline & Z (Moderator) &, 381 & ,127 & ,355 & 3,007 & ,005 \\
\hline & Interaksi X1*Z & 1,012 &, 353 & ,797 & 2,865 & 007 \\
\hline
\end{tabular}

Sumber: Data Primer yang Diolah 2020

Berdasarkan tabel di atas diketahui nilai signifikan tekanan anggaran waktu dan etos kerja sebesar 0,007. Dilihat dari derajat kesalahan nilai tersebut lebih keci $(\alpha=0,05)(0,007<$ 0,05). Maka dari itu dapat diambil kesimpulan bahwa etos kerja memperkuat pengaruh tekanan anggaran waktu terhadap mutu kinerja auditor. Interaksi antara tekanan anggaran waktu dan etos kerja memiliki hasil yang tergolong dalam quasi moderasi, artinya tekanan anggaran waktu berpengaruh signifikan terhadap mutu kinerja auditor dan juga interaksi antara tekanan anggaran waktu dengan etos kerja memiliki hasil berpengaruh signifikan terhadap mutu kinerja auditor. Dengan ini hipotesis keempat $\left(\mathrm{H}_{4}\right)$ dalam penelitian ini diterima. 


\section{Pengujian Model 3}

Tabel 13. Hasil Uji Koefisien Determinasi Model 3

\begin{tabular}{|c|c|c|c|}
\hline \multicolumn{4}{|c|}{ Model Summary } \\
\hline Model & $\mathrm{R}$ & $\mathrm{R}_{2}$ & Estimasi Standar Eror \\
\hline 1 &, $701^{\mathrm{a}}$ & 491 & ,44293 \\
\hline
\end{tabular}

Sumber: Data Primer yang Diolah 2020

Tabel di atas, menjelaskan bahwa nilai $\mathrm{R}_{2}$ (koefisien determinasi) sebesar 0,491 atau 49,1\%. Yang artinya variabel mutu kinerja auditor bisa dijelaskan oleh variabel integritas, etos kerja, dan variabel interaksi antara integritas dengan etos kerja sebesar $49,1 \%$ dan selebihnya 50,9\%, dijelaskan oleh variabel lain diluar dari penelitian ini.

Tabel 14. Hasil Uji t Model 3

\begin{tabular}{|c|c|c|c|c|c|c|}
\hline \multicolumn{7}{|c|}{ Coefficients $^{\mathrm{a}}$} \\
\hline \multirow{2}{*}{\multicolumn{2}{|c|}{ Model }} & \multicolumn{2}{|c|}{ Unstandardized Coefficients } & \multirow{2}{*}{$\begin{array}{c}\text { Standardized Coefficients } \\
\text { Beta }\end{array}$} & \multirow[b]{2}{*}{$\mathrm{T}$} & \multirow[b]{2}{*}{ Signifikansi } \\
\hline & & $\mathrm{B}$ & Standart Error & & & \\
\hline \multirow[t]{4}{*}{1} & (Constant) & 1,097 &, 114 & & 9,629 &, 000 \\
\hline & $\mathrm{X} 2$ & ,440 & ,119 & ,437 & 3,698 & ,000 \\
\hline & $\mathrm{Z}$ (Moderator) & 1,103 & , 177 &, 713 & 6,231 &, 000 \\
\hline & Interaksi $\mathrm{X} 2 * \mathrm{Z}$ & 239 & ,108 & 214 & 2,213 & ,022 \\
\hline
\end{tabular}

Pada tabel di atas diketahui nilai sign interaksi integritas dan etos kerja yaitu 0,022. Dilihat dari derajat kesalahan nilai tersebut lebih kecil $(\alpha=0,05)(0,022<0,05)$. Maka dari itu dapat diambil kesimpulan bahwa etos kerja memperkuat pengaruh integritas terhadap mutu kinerja auditor. Interaksi integritas dan etos kerja memiliki hasil yang tergolong dalam quasi moderasi, artinya integritas berpengaruh signifikan terhadap mutu kinerja auditor dan juga hasil interaksi integritas dengan etos kerja berpengaruh signifikan terhadap mutu kinerja auditor. Dengan ini hipotesis kelima $\left(\mathrm{H}_{5}\right)$ dalam penelitian ini diterima.

\section{Pengujian Model 4}

Tabel 15. Hasil Uji Koefisien Determinasi Model 4

\begin{tabular}{|c|c|c|c|c|}
\hline \multicolumn{5}{|c|}{ Model Summary ${ }^{b}$} \\
\hline Model & $\mathrm{R}$ & $\mathrm{R}_{2}$ & Adjusted $\mathrm{R}_{2}$ & Std. Error of the Estimate \\
\hline 1 &, $877^{\mathrm{a}}$ & ,770 & ,749 & ,29797 \\
\hline
\end{tabular}

Sumber: Data Primer yang Diolah 2020

Berdasarlan tabel di atas menjelaskan bahwa nilai $\mathrm{R}_{2}$ (koefisien determinasi) sebesar 0,770 atau 77\%. Yang artinya variabel mutu kinerja auditor bisa dijelaskan oleh variabel motivasi, etos kerja, dan variabel interaksi antara motivasi dengan etos kerja sebesar $77 \%$ dan sisanya yaitu $23 \%$, dijelaskan oleh variabel lain diluar dari penelitian ini. 
Tabel 16. Hasil Uji t Model 4

\begin{tabular}{|c|c|c|c|c|c|c|}
\hline \multicolumn{7}{|c|}{ Coefficients $^{\mathbf{a}}$} \\
\hline \multirow{2}{*}{\multicolumn{2}{|c|}{ Model }} & \multicolumn{2}{|c|}{ Unstandardized Coefficients } & \multirow{2}{*}{$\begin{array}{c}\text { Standardized Coefficients } \\
\text { Beta }\end{array}$} & \multirow[b]{2}{*}{$\mathrm{T}$} & \multirow[b]{2}{*}{ Sig. } \\
\hline & & $\mathrm{B}$ & Std. Error & & & \\
\hline \multirow[t]{3}{*}{1} & (Constant) & 3,324 &, 387 & & 8,589 &, 000 \\
\hline & $\mathrm{X} 3$ &, 716 & ,098 & ,701 & 7,306 & 000 \\
\hline & Z (Moderator) & ,387 & , 109 & ,321 & 3,550 & 001 \\
\hline
\end{tabular}

Pada tabel di atas diketahui nilai signifikan interaksi motivasi dan etos kerja sebesar 0,000. Dilihat dari derajat kesalahan nilai tersebut lebih kecil $(\alpha=0,05)(0,000>0,05)$. Maka dapat diambil kesimpulan bahwa etos kerja memperkuat pengaruh motivasi terhadap mutu kinerja auditor. Interaksi motivasi dan etos kerja memiliki hasil yang tergolong dalam quasi moderasi, artinya motivasi berpengaruh signifikan terhadap mutu kinerja auditor dan hasil interaksi motivasi dengan etos kerja berpengaruh signifikan terhadap mutu kinerja auditor. Dengan ini hipotesis keenam $\left(\mathrm{H}_{6}\right)$ dalam penelitian ini diterima.

\subsection{Pembahasan}

Dapat kita lihat dari hasil penelitian diketahui bahwa tekanan anggaran waktu memiliki koefisien positif terhadap mutu kinerja auditor. Hal ini menunjukkan bahwa tekanan anggaran waktu memiliki pengaruh yang searah terhadap mutu kinerja auditor. Dengan kata lain, semakin tinggi tingkat tekanan anggaran waktu yang diberikan kepada auditor maka akan berdampak pada kedisiplinan maupun ketelitian seorang auditor dalam hal ini yaitu kinerja auditor akan semakin bermutu. Dalam hasil penelitian ini didukung oleh Azizah Nurul (2015), yang menyatakan bahwa kinerja auditor itu dipengaruhi oleh tekanan anggaran waktu. Dengan demikian membuktikan bahwa derajat tinggi rendahnya tekanan anggaran waktu yang diberikan seorang auditor dalam dalam melaksanakan tugas auditnya, maka semakin baik pula kinerja auditor tersebut [8].

Dilihat dari hasil penelitian ini diketahui bahwa integritas memiliki koefisien positif terhadap mutu kinerja auditor. Hal ini menjelaskan bahwa integritas memiliki pengaruh yang searah terhadap mutu kinerja auditor. Dengan kata lain, semakin auditor memiliki integritas yang tinggi maka akan berdampak pada semakin baik mutu kinerja auditnya. Hasil penelitian ini sejalan oleh Yuskar \& Selly (2011), yang menyatakan bahwa kinerja auditor itu dipengaruhi oleh integritas [9]. Hal ini menunjukkan bahwa tingginya integritas seseorang maka semakin baik kinerja auditor tersebut.

Dilihat dari hasil penelitian ini diketahui bahwa motivasi memiliki koefisien positif terhadap mutu kinerja auditor. Hal ini menjelaskan bahwa motivasi memiliki pengaruh yang 
searah terhadap mutu kinerja auditor. Dengan kata lain, semakin auditor memiliki motivasi yang kuat dalam bekerja maka akan berdampak pada semakin baik kinerja audit dan kualitas hasil auditnya. Hasil penelitian ini didukung oleh Honawati (2016) yang menyatakan bahwa kinerja auditor itu dipengaruhi oleh motivasi [10]. Hal ini menunjukkan bahwa semakin tinggi tingkat motivasi seseorang maka akan semakin berkualitas kinerja auditor tersebut.

Diketahui dari hasil penelitian ini bahwa terdapat pengaruh yang positif dan signifikan dari etos kerja serta memperkuat hubungan antara tekanan anggaran waktu dengan mutu kinerja auditor. Hal ini berarti dengan adanya etos kerja yang tinggi akan membuat kinerja auditor semakin baik dan berkualitas terhadap tekanan waktu yang dia hadapi.

Berdasarkan dengan hasil penelitian bahwa etos kerja mempunyai pengaruh yang positif dan signifikan serta memperkuat hubungan antara integritas dengan mutu kinerja auditor. Hal ini berarti dengan adanya etos kerja yang tinggi akan membuat integritas yang dimiliki akan semakin berpengaruh dengan baik terhadap mutu kinerja auditor.

Berdasarkan hasil penelitian ditemukan bahwa etos kerja berpengaruh signifikan dan memperkuat hubungan motivasi dengan mutu kinerja auditor. Ini menunjukkan bahwa adanya etos kerja yang tinggi akan akan mempengaruhi motivasi seseorang untuk membuat kinerjanya semakin berkualitas.

\section{KESIMPULAN}

Tekanan anggaran waktu, integritas, motivasi berpengaruh positif dan signifikan terhadap mutu kinerja auditor. Artinya, bahwa semakin tinggi tingkat tekanan anggaran waktu, integritas, dan motivasi yang diberikan auditor dan dimiliki seorang auditor maka kinerja auditnya yang didapatkan akan semakin berpengaruh dan semakin baik.

Etos kerja berpengaruh positif dan signifikan terhadap hubungan antara tekanan anggaran waktu, integritas, dan motivasi dengan mutu kinerja auditor. Artinya, etos kerja yang dimiliki seorang auditor sangat mendukung dan memperkuat adanya hubungan antara tekanan anggaran waktu, integritas, dan motivasi dengan kinerja auditor yang dihasilkan.

\section{SARAN}

Untuk objek penelitian (Inspektorat Daerah Provinsi Sul-Sel) yaitu para Auditor yang bekerja di kantor tersebut, sekiranya agar dapat meningkatkan tingkat tekanan anggaran waktu, integritas, motivasi, serta etos kerjanya lagi dalam melakukan proses audit guna menciptakan kinerja audit dan hasil audit yang sangat berkualitas. Walaupun integritas, motivasi, dan etos 
kerja yang dimiliki sudah cukup memadai, akan tetapi jika di tingkatkan lebih tinggi akan lebih memuaskan dalam proses mengaudit.

\section{DAFTAR PUSTAKA}

[1] D. O. Ruspina, "Pengaruh Kinerja Aparatur Pemerintah Daerah, Pengelolaan Keuangan Daerah, dan Sistem Pengendalian Internal Pemerintah (SPIP) Terhadap Penerapan (Good Governance) Studi Empiris Pada Pemerintahan Kota Padang," Universitas Negeri Padang, 2013.

[2] N. M. A. Ristanti and Dkk, "Pengaruh Sistem Pengendalian Intern, Pengelolaan Keuangan Daerah dan Komitmen Organisasi Terhadap Penerapan Good Governance," E-Jurnal Akunt., vol. 2, no. 1, 2014.

[3] Mardiasmo, Perpajakan Edisi Revisi. Yogyakarta: Andi, 2009.

[4] Pemerintah Republik Indonesia, Peraturan Pemerintah Republik Indonesia No. 12 Tahun 2017 Tentang Pembinaan dan Pengawasan Penyelenggaraan Pemerintahan Daerah. 2017.

[5] Pemerintah Republik Indonesia, Peraturan Pemerintah Dalam Negeri Nomor 64 Tahun 2007 Tentang Peran dan Fungsi Inspektorat Provinsi, Kota/Kabupaten. 2007.

[6] Pemerintah Daerah Sulawesi Selatan, Peraturan Daerah Gubernur Sulawesi Selatan No. 9 Tahun 2008 Tentang Tugas Inspektorat Provinsi Sulawesi Selatan. 2008.

[7] Anti Corruption Committee (ACC), "Progres Report Anti Corruption Committee (ACC) Sulawesi 2015-2017."

[8] N. Azizah, "Pengaruh Ketidakjelasan Peran, Konflik Peran, Profesionalisme, Budaya Organisasi, dan Tekanan Anggaran Waktu (Time Budget Pressure) Terhadap Kinerja Auditor," Universitas Negeri Semarang, 2015.

[9] H. Yuskar and S. Devisia, "Pengaruh Independensi Auditor, Komitmen Organisasi, Pemahaman Good Governance, Integritas Auditor, Budaya Organisasi, dan Etos Kerja Terhadap Kinerja Auditor,” Universitas Muhammadiyah Surakarta, 2011.

[10] Honawati, "Pengaruh Motivasi Kerja dan Komitmen Organisasi Terhadap Kinerja Karyawan dengan Etos Kerja Sebagai Variabel Moderasi," Universitas Negeri Yogyakarta, 2016. 